\title{
ENDOSCOPIC RESECTION OF ESOPHAGEAL LIPOSARCOMA
}

\author{
R. Temes, MD, ${ }^{\text {a }}$ P. Quinn, MD, ${ }^{\mathrm{b}}$ M. Davis, MD,${ }^{\mathrm{c}} \mathrm{S}$. Endara, MD, ${ }^{\mathrm{a}}$ F. Follis, MD, ${ }^{\mathrm{a}} \mathrm{S}$. Pett, MD, ${ }^{\mathrm{a}}$ and J. Wernly, MD, ${ }^{\mathrm{a}}$ \\ Albuquerque, N.M.
}

Liposarcoma is the most common sarcoma of the lower extremities and retroperitoneum. ${ }^{1}$ It is rare in the aerodigestive tract. Only six previous cases of esophageal liposarcomas and 16 cases of supraglottic laryngeal liposarcoma have been reported..$^{1-5}$ We report a case of this unusual tumor, describe endoscopic ultrasound findings, and report its treatment by endoscopic resection.

Clinical summary. A 69-year-old male Mexican native had a 3-month history of dysphagia and foreign body sensation in the neck. Barium swallow demonstrated a mobile, pedunculated $12 \mathrm{~cm}$ mass arising approximately at the level of the cricopharyngeus. Computed tomographic scan showed the mass to be fat density with subtle areas of soft tissue density. Endoscopic examination with the patient under general anesthesia revealed the tumor to have a normal mucosal lining and gross appearance consistent with fat (Fig. 1). Endoscopic ultrasonography showed the tumor to have fat density and subtle areas of inhomogeneity (Fig. 2). Although the tumor was within the esophagus, the origin was from the supraglottic larynx. The mass was everted through the mouth and several major projections arising from discrete contiguous stalks were noted. With the use of endoscopic suturing instruments inserted

From the University of New Mexico Health Sciences Center, Division of Thoracic and Cardiovascular Surgery, ${ }^{\mathrm{a}}$ Division of Gastroenterology, ${ }^{\mathrm{b}}$ and Department of Radiology, ${ }^{\mathrm{c}}$ Albuquerque, N.M

Received for publication Feb. 19, 1998; accepted for publication March 11, 1998.

Address for reprints: R. Thomas Temes, MD, Department of Surgery, Division of Thoracic and Cardiovascular Surgery, 2211 Lomas Blvd., NE, Albuquerque, NM 87122.

J Thorac Cardiovasc Surg 1998;116:365-7

Copyright (c) 1998 by Mosby, Inc.

0022-5223/98 \$5.00+ $0 \quad \mathbf{1 2 / 5 4 / 9 0 6 6 7}$ through the rigid esophagoscope, the stalks were suture ligated and the masses were resected (Fig. 3). Pathologic examination demonstrated well-differentiated liposarcoma with diseased margins. The patient was offered laryngectomy and radiation therapy but declined further treatment. His preoperative symptoms immediately resolved and he returned to Mexico.

Discussion. Sarcomas of the upper aerodigestive tract are rare. When located within the esophagus, the histologic types are fibrosarcoma, leiomyosarcoma, rhabdomyosarcoma, carcinosarcoma, pseudosarcoma, and reticulum cell sarcoma. In total, these tumors comprise fewer than $0.5 \%$ of esophageal malignant tumors. ${ }^{1}$ Liposarcomas of the esophagus also are rare, only six previous cases having been reported. ${ }^{1-5}$

Liposarcomas of the supraglottic larynx are also extremely unusual. Only 16 have been reported. ${ }^{2}$ Whether this tumor should be considered esophageal or laryngeal is debatable. Because of the presentation, location, and treatment of the tumor, we considered it to be esophageal.

The histologic types of liposarcomas are well differentiated, myxoid, round cell, and pleomorphic. ${ }^{2}$ Prognosis and risk for local recurrence depend on histologic features. Well-differentiated and myxoid types have 5-year survivals of $75 \%$ to $100 \%$ and local recurrence rates of $50 \% .^{2}$ Other types are associated with lower survivals and higher recurrence rates. ${ }^{2}$

Patients with esophageal liposarcoma have dysphagia, weight loss, foreign body sensation, and rarely gastrointestinal bleeding or asphyxia. ${ }^{1-5}$ Evaluation has traditionally been with barium swallow and endoscopy. More recently, computed tomographic and magnetic resonance imaging scans have been used. These demonstrate the fatty nature of the tumors but cannot reliably differentiate malignant from benign lesions. ${ }^{3}$ Findings of inhomogeneous appearance on computed tomographic scan and multifocal sites of origin have been reported in liposarco- 


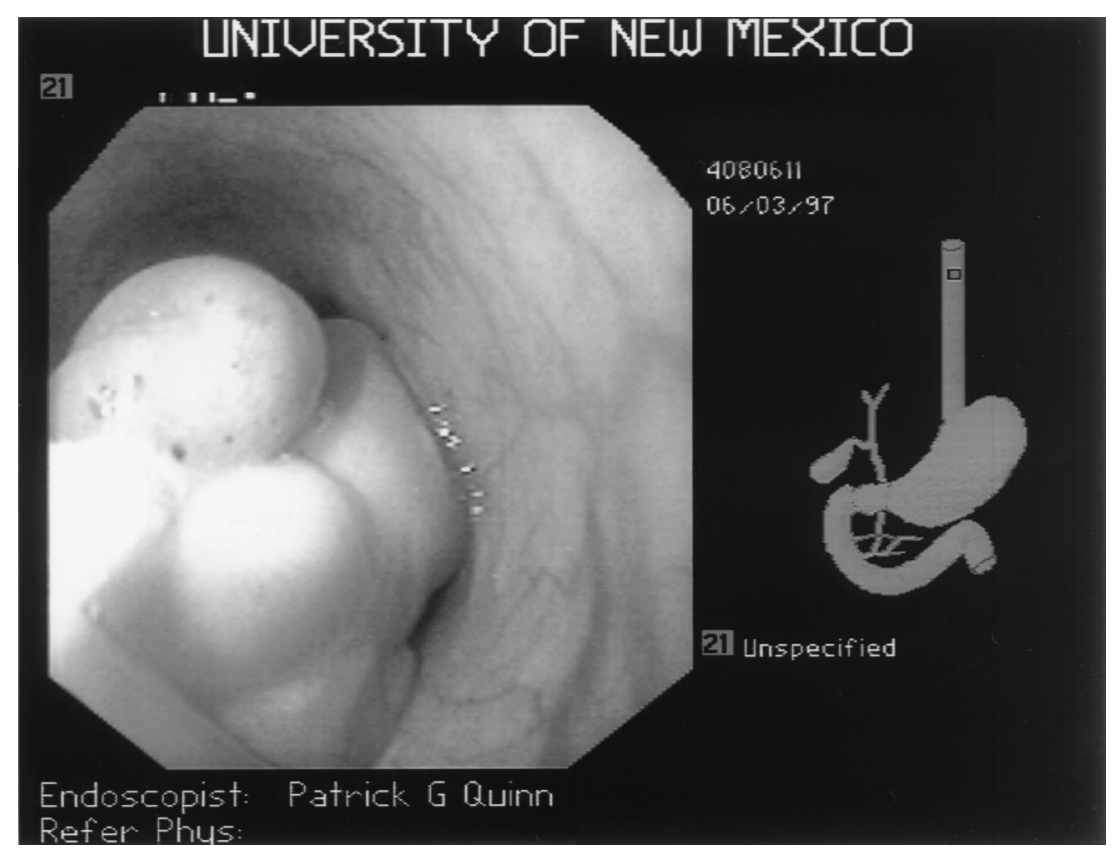

Fig. 1. Endoscopic view of esophageal liposarcoma.

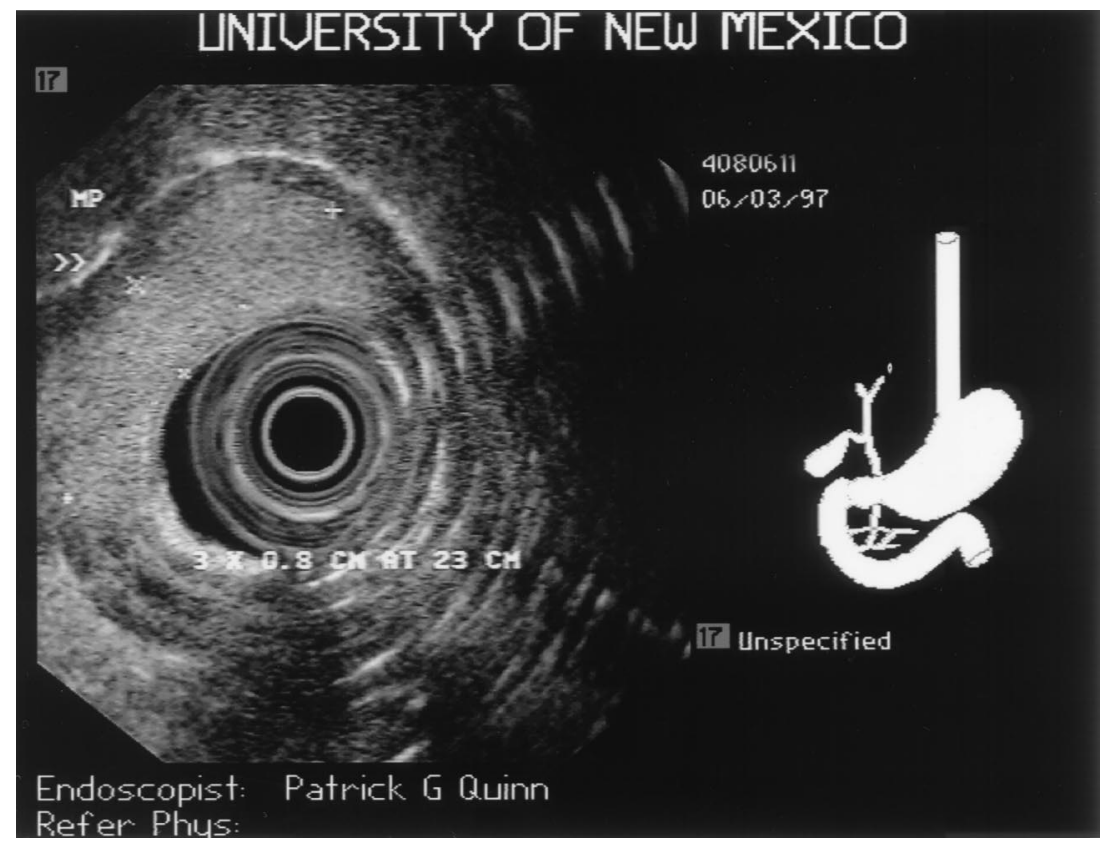

Fig. 2. Endoscopic ultrasonogram of esophageal liposarcoma.

mas of the esophagus and may be indicators of malignancy. ${ }^{3}$ Esophageal ultrasound has not been previously used in evaluation of these patients. We found that it confirmed the fatty nature of the tumor and suggested complexity of the mass consistent with malignancy. Biopsies of esopha- geal liposarcomas have revealed only benign squamous epithelium and have not been diagnostic. ${ }^{4,5}$

Five of the previously reported esophageal liposarcomas arose from the cervical esophagus and one from the thoracic esophagus. ${ }^{1-5}$ Surgical resection was performed 


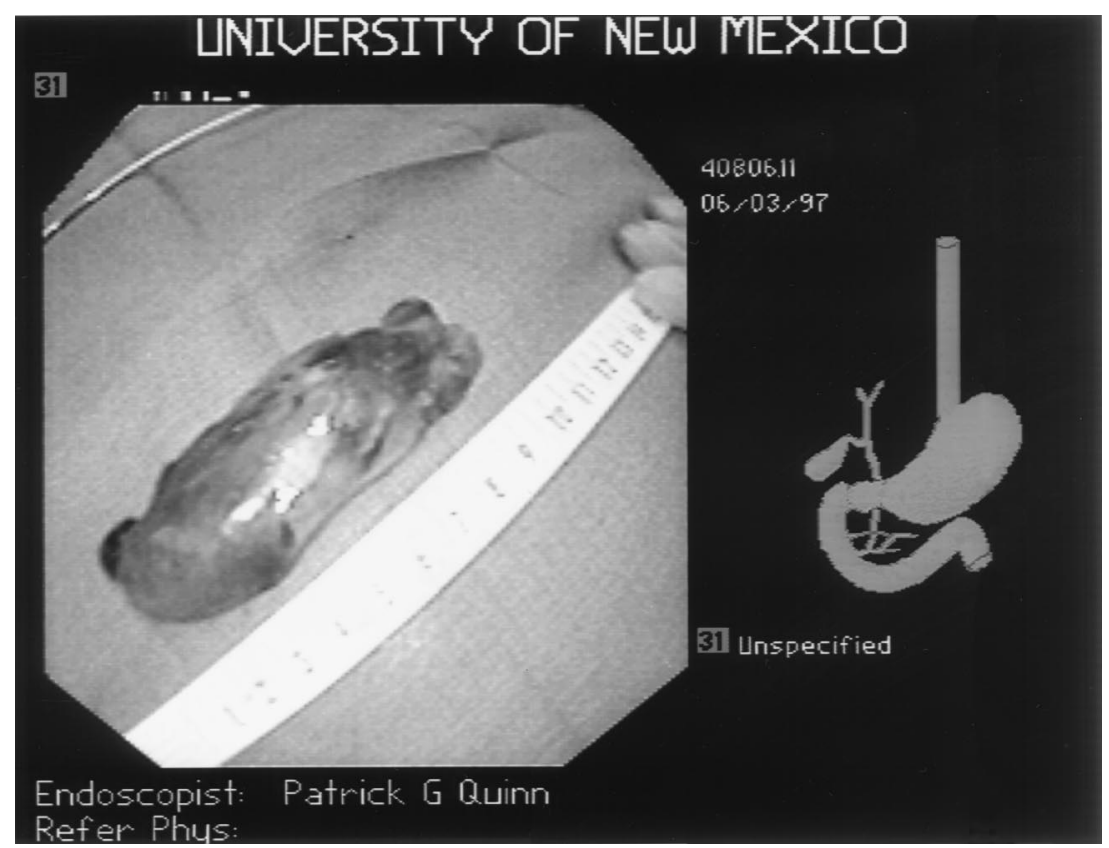

Fig. 3. Resected esophageal liposarcoma.

in all cases. Techniques varied and included transcervical, transthoracic, and transabdominal resections. ${ }^{1-5}$ As in liposarcomas in other locations, obtaining histologically free margins is critical but may be impossible, even with extended resections. ${ }^{5}$ In some esophageal liposarcomas the pedicle is uninvolved. ${ }^{1,3}$ In these patients, endoscopic resection may result in cure. Alternatively, endoscopic resection may provide palliation to patients with unresectable disease or may be followed with surgical resection in those with diseased margins. Although endoscopic excision has been previously attempted, this case is the first successful application of this technique. ${ }^{3}$

Local recurrence has occurred in approximately $50 \%$ of well-differentiated and myxoid liposarcomas at all sites and in approximately $80 \%$ of round cell and pleomorphic liposarcomas at all sites. ${ }^{2}$ In patients with esophageal liposarcoma, local recurrence has been reported in at least one patient with diseased margins. ${ }^{5}$ Liposarcoma at other sites has been shown to be radiosensitive. ${ }^{1-3}$ We recommended that our patient undergo either radical surgical reexcision or adjuvant radiation therapy. He refused both.

Liposarcomas of all sites have been associated with other primary malignant tumors in approximately $12 \%$ of cases. ${ }^{1}$ Of the six previously reported esophageal liposarcomas, two were associated with confirmed or suspected lung cancer. ${ }^{1,5}$ Our patient had no other known malignant disease.

Survival for liposarcomas in general is dependent on histologic type and location. On the six previously re- ported esophageal liposarcomas, five have been myxoid and one well differentiated. ${ }^{1-5}$ Our patient had welldifferentiated liposarcoma. Survival in the previous cases has been 7 to 104 months. ${ }^{1-5}$ Our patient left the country and was lost to follow-up 1 month after resection.

This case is remarkable because of the rarity of the tumor. It is also notable because of the use of esophageal ultrasound in diagnosis. Finally, it demonstrates that endoscopic resection is technically possible and in certain instances may be appropriate therapy for this tumor.

\section{REFERENCES}

1. Mansour KA, Fritz RC, Jacobs DM, Vellios F. Pedunculated liposarcoma of the esophagus: a first case report. J Thorac Cardiovasc Surg 1983;86:447-50.

2. Stewart MG, Schwartz MR, Alford BR. Atypical and malignant lipomatous lesions of the head and neck. Arch Otolaryngol Head Neck Surg 1994;120:1151-5.

3. Boggi U, Viacava P, Naccarato AG, Cristoforo Giulianotti $P$, Di Candio G, Battolla L, et al. Giant pedunculated liposarcomas of the esophagus: literature review and case report. Hepatogastroenterology 1997;44:398-407.

4. Cooper GJ, Boucher NR, Smith JH, Thorpe JA. Liposarcoma of the esophagus. Ann Thorac Surg 1991;51:1012-3.

5. Yates SP, Collins MC. Case report: recurrent liposarcoma of the oesophagus. Clin Radiol 1990;42:356-8. 